\title{
Multi-Modal Mingling: Queering BIM through Transportation Hub Design and Networks
}

\section{DANELLE BRISCOE}

University of Texas at Austin
The accumulative nature of our post-digital/ post-natural moment surfaces in the context of urban transportation networks. While massive amounts of ubiquitous personal GPS data records user physical activity, planes, trains and automobiles share and deliver real-time information related to mobility routes. For most cities, systems build-up additionally holds both planetary and quotidian crises: heat island effects overlay with infrastructural neglect, terrorist attacks in subway stations merge with lack of user provision, and air quality collapses under the daily reality of the Anthropocene. Such a collision of hierarchies not only affect the urban extremities of transportation, but moreover the way we experience, practice and teach architecture.

One could argue that such messiness contradicts the precision and completeness of the often "required for construction" Building Information Modelling (BIM) realm. Not unlike Jacob Gaboury's writings on queer computing, queering BIM legitimizes the critique of who and what the platform identifies, recognizes and makes visible. More broadly, the process of "multi-modal mingling" holds promise for radical practices of information design in an otherwise lackluster realm of urban/ regional transport planning. A process for both research and academic studio entails moving past default settings and standards to include the odd, diverse and discounted that exists in this accumulative world of transport.

This project presents the research findings and pedagogical studio agenda afforded by a grant from USDOT University Transportation Center and Center of Cooperative Mobility for Competitive Megaregions (CM2). By focusing on the human scale and objects of transportation related inhabitation; identifying the network hub devoid of its envelope of "architecture." Sharon Mattern's "A City is Not a Computer"1 reminds us to consider and question society's relationship to technology so by this premise, built form is not necessarily programmable and able to tidy into rational order as we once knew it.

Student development of "User Based Scenarios" collapses the hierarchies of governance and predicts relevant circumstances of transit integration. The congestion of a suburban commuter for example to an urban workplace holds all the data but less legibility in the queered BIM and survives off feedback related to energy spent and offered with each interaction and system assembly. A woman selling churros in the subway for example hold agency as a deduced and digitized modelled family in order to overlap, speculate and build upon in the project. The collision of hierarchies challenge the students' design perceptions using the global issues at hand and how local circumstances affect them. This causes us to rethink the practice in terms of the zonal logics and intermediation of networks and technologies deemed "smart"2 Thus, pedagogy is empowered to frame (and benefit from) a knowledge base of scale conflation of advanced and alternative transportation design elements and their representation, further promoting diversity and environmental optimization for the advancement of practice.

\section{ENDNOTES}

1 Shannon Mattern, "A City Is Not a Computer," Places Journal 18 (February 2017). https://doi.org/10.22269/170207.

2 Orit Halpern, Robert Mitchell, and Bernard Dionysius Geohagan, "The Smartness Mandate: Notes toward a Critique," Grey Room 68 (Summer 2017). https://doi. org/10.1162/GREY_a_00221. 

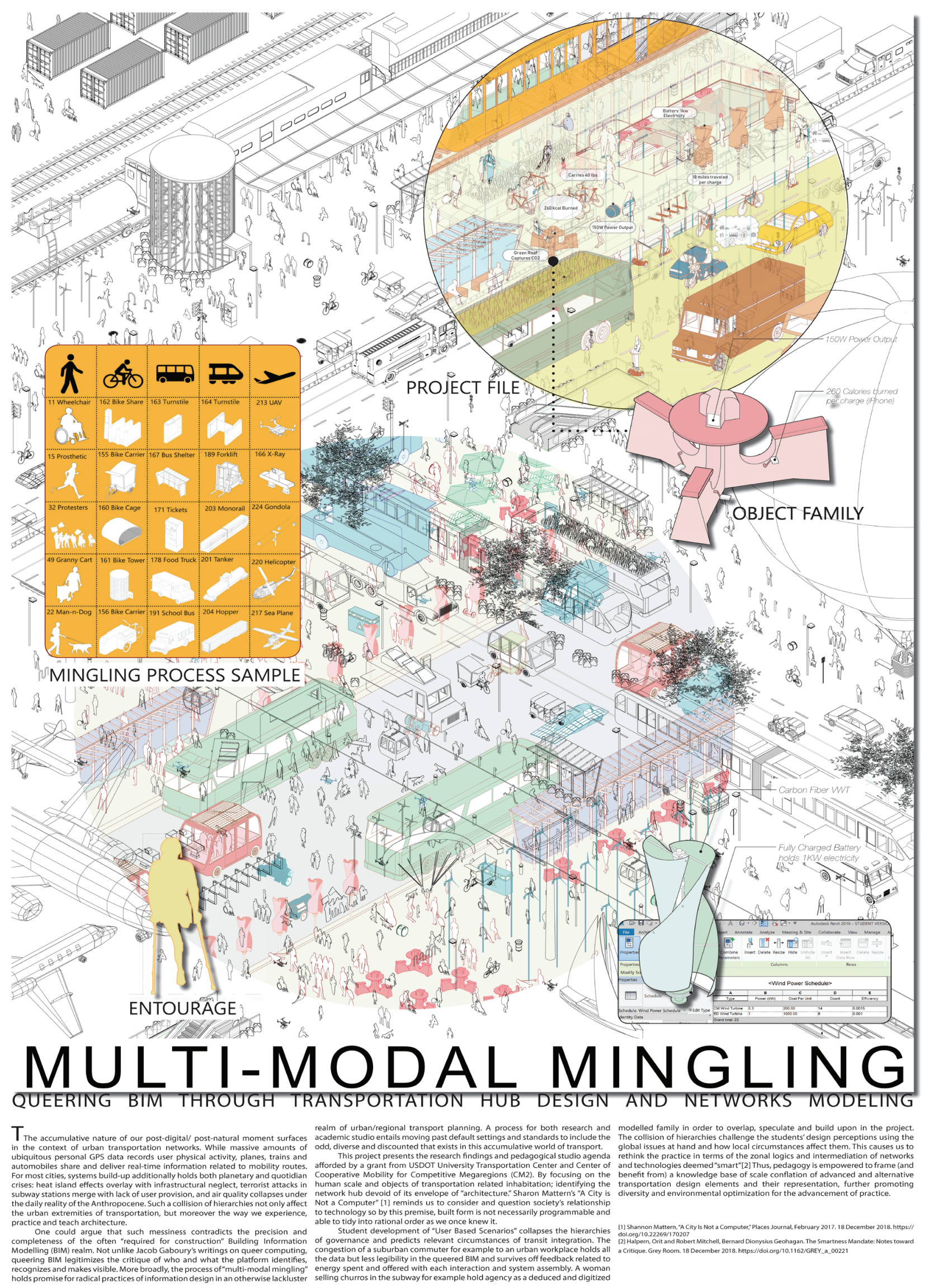